\title{
Troballes ePigràFiques a la VIL·LA ROMANa de l’Horta Vella (Bétera, VALÈNCIA)
}

FERRAN ARASA I GIL ${ }^{1}$ (1) JOSEP M. BURRIEL ALBERICH², JOSÉ LUIS JIMÉNEZ SALVADOR ${ }^{1}$

(1) Dpt. Prehistòria, Arqueologia i $\mathrm{H}^{\mathrm{a}}$ Antiga. Universitat de València. Ferran.Arasa@uv.es, Jose.L.Jimenez@uv.es

(2) Museu Arqueològic Municipal de Moncada.museu@moncada.es

La vil·la romana de l'Horta Vella (Bétera, l'Horta Nord), situada a la vora del límit septentrional de la pertica valentina, s'excava des de l'any 2001 per un equip dirigit per J. L. Jiménez Salvador i J. M. Burriel Alberich (fig. 1). Al llarg d'aquests anys s'hi han pogut descobrir uns balnea i restes d'ocupació posterior d'època visigòtica, paleoandalusí i contemporània (Jiménez et al. 2008; 2011; 2012; 2013: 213-214). En aquesta nota presentem tres nous fragments epigràfics trobats en la campanya del 2014, els primers documentats fins ara a la vil $\cdot \mathrm{la}^{1}$. Aparegueren al sector $\mathrm{N}$ del jaciment, on es procedí a treure el pedregar acumulat al seu voltant en època contemporània com a conseqüència de l'activitat agrícola, tasca que ja s'havia començat en la campanya de l'any 2009, però que no s'havia pogut finalitzar. Dos dels fragments es trobaren a la UE 1475 (fig. 3, 5), un abocament d'època contemporània amb abundants pedres, algunes treballades en forma de carreu, barrejades amb terra agrícola i cendres, així com deixalles contemporànies (plàstic), amb alguns materials antics com fragments de tegulae, alguns fragments de ceràmica del període imperial i tardana i de vidre. El tercer fragment (fig. 2), que pertany a un dels dos monuments trobats a l'anterior UE, aparegué a la UE 1476, que correspon a un marge agrícola d'època contemporània construït amb carreus i blocs de gres.

1) Es tracta de dos fragments d'un mateix monument, el primer dels quals (a) correspon a la part superior i conserva algunes lletres de les dues primeres línies, i el segon (b) pertany a la part inferior i conserva algunes lletres de les dues darreres línies. L'epígraf era una llosa possiblement de forma paral-lelepipèdica de calcària grisa fosca amb vetes blanques, un tipus de pedra freqüent en aquesta zona que es coneix com a 'pedra de Sagunt'. El camp epigràfic, que conserva marques de treball, està situat en un plànol rebaixat 4-5 $\mathrm{mm}$, de manera que apareix rodejat per una fascia llisa, un tipus d'emmarcament no molt freqüent que trobem per exemple a Valentia en el pedestal de $C$. Virius C.f. Gal. Nepos (IRPV V, 39). Les seues proporcions eren considerables i devia formar part d'una construcció monumental de tipus indeterminat, a la qual possiblement pertanyen alguns fragments d'elements motlurats recuperats al mateix jaciment. Els dos fragments no tenen connexió i no permeten precisar 


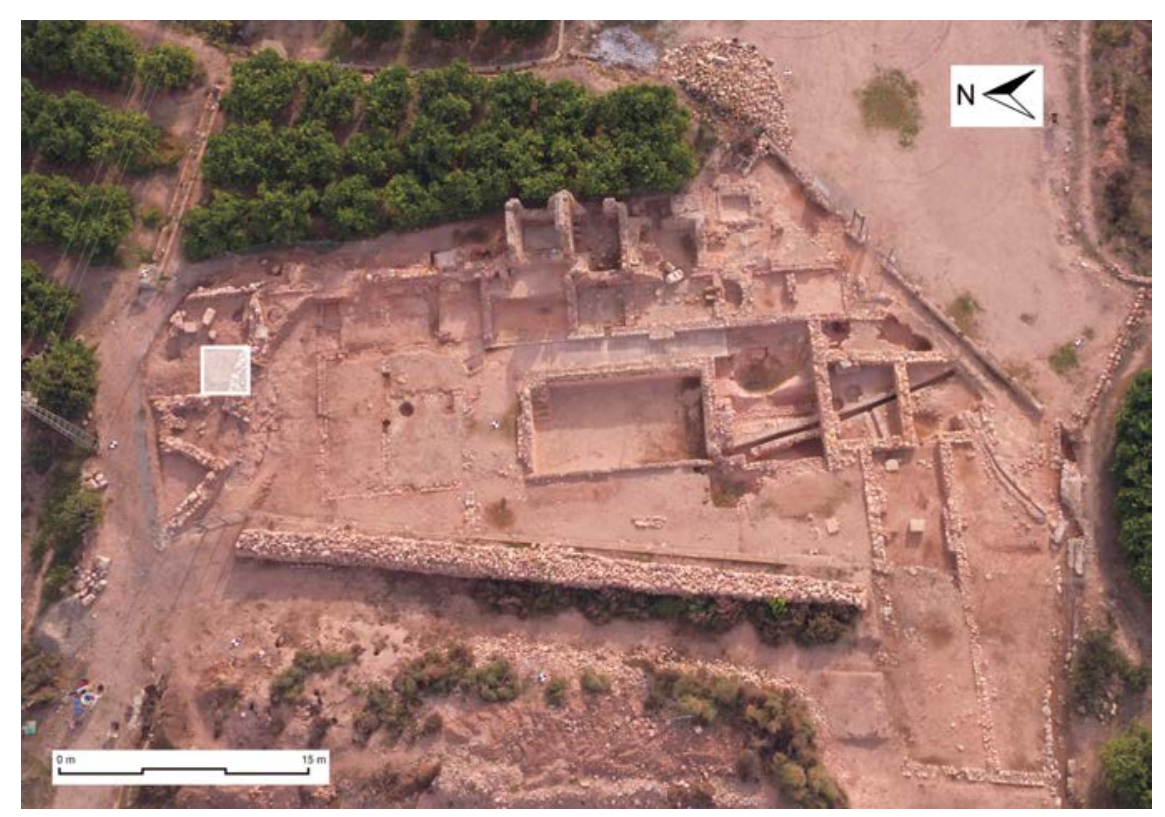

Fig. 1: Fotografia zenital de la vil·la amb el lloc de la troballa dels fragments epigràfics.

l'altura del monument, que era major de $64 \mathrm{~cm}$. Segons la nostra interpretació del text, el primer (a) correspon a la zona centreesquerra de la part superior, i el segon (b) devia situar-se cap a l'angle inferior dret.

1-a) El costat superior, que només està desbastat, sembla l'original. Les seues dimensions són 31 x 23,5 x 26 cm (fig. 2). La fascia llisa que limita el camp epigràfic per la part superior té una amplària de $7,5 \mathrm{~cm}$. L'altura de les lletres és de $6,5 \mathrm{~cm}$, el marge superior de $3,5 \mathrm{~cm}$ i la interlineació de $3 \mathrm{~cm}$. La lletra és elegant, de solc un poc irregular, i compta amb reforços. En la primera línia es conserva al principi un punt triangular i a continuació senceres les lletres VI, seguides d'una tercera incompleta per la fractura del costat dret que pot ser una $\mathrm{P}$ o una $\mathrm{R}$. Pot tractar-se, doncs, de la seqüència VIP/VIR- que correspondria al nomen o al cognomen del personatge honorat. De la segona línia es conserven tres lletres incompletes, de les quals la primera pot ser F o E, la segona una I i la tercera una altra I o L. Podria tractar-se de la filiació expressada amb l'abreviatura FIL, no molt freqüent.

1-b) El costat inferior, que només està desbastat, també podria ser l'original. Les seues dimensions són $31 \mathrm{x}$ 41 x 23,5 cm (fig. 3). L'amplària de la fascia llisa que es conserva a la banda inferior és de $6 \mathrm{~cm}$. L'altura de les lletres és de 6,5 cm, el marge inferior de $10,5 \mathrm{~cm}$ i la interlineació de $3 \mathrm{~cm}$. La lletra és semblant a la del fragment anterior. En la primera línia només es conserva l'extrem inferior d'una O. En la segona, a la vora esquerra es veu el reforç horitzontal d'una lletra de la qual no se'n conserva la prolongació cap amunt. A continuació es poden llegir les lletres AESI, seguides d'una N mig esborrada i d'una $\mathrm{A}$ incompleta però que es poden reconèixer i completen la sequiència -]AESINA. Es tracta d'un nom personal que, per trobar-se al final de la darrera línia, deu correspondre al cognom de la dedicant.

$$
\begin{aligned}
& {[--] \cdot \operatorname{Vir}[i---]} \\
& {[--] \text { fill(i-) [-- - ] }} \\
& ---- \text { ? } \\
& {[--] O[---]} \\
& {[- \text { - ]aesina. }}
\end{aligned}
$$

En el text trobem dues parts de sengles noms, l'inici d'un a la primera línia, i el final d'un altre a la darrera (fig. 4). Si, com és normal en el context d'una villa, es tracta d'un epígraf funerari, el primer hauria de correspondre al nom del difunt i el segon al de la dedicant. Pel que fa al primer, la presència d'un punt a l'esquerra hi deixa obertes dues possibilitats: que es tracte del punt que segueix a l'abreviatura del prenom, i que per tant siga el nom, de manera que el fragment seria pròxim a l'inici del text i a la vora esquerra del monument; o que el punt separe un altre component del nom com la filiació o la tribu i es tracte del cognom, el que no considerem tan 


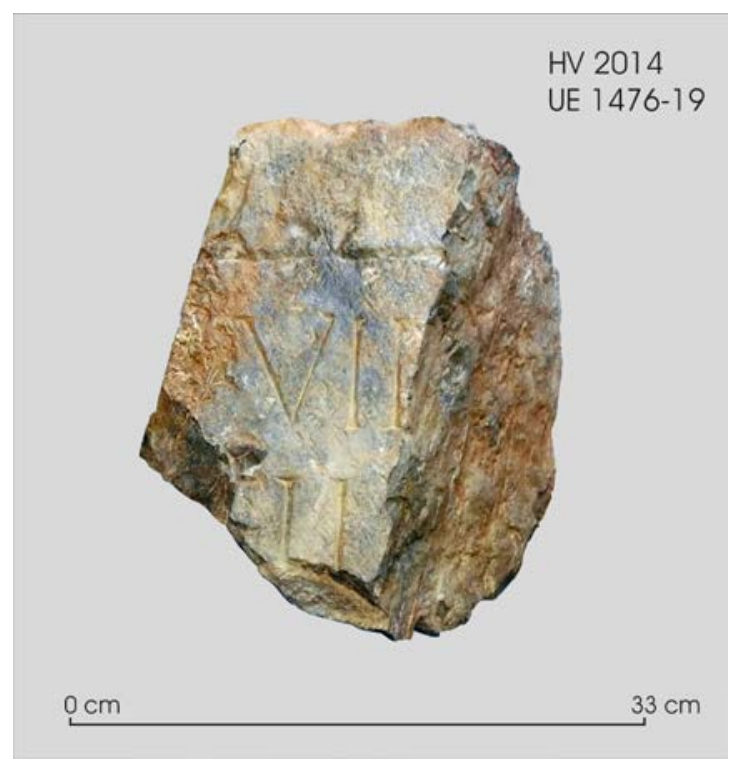

Fig. 2: Fragment núm. 1-a.

probable. Si considerem aquesta possibilitat, hi ha diversos casos que comencen per VIR-: Virani, Virgilianus, Virginia, Viriatis, Viriatus, Virius, Vironicus, Virona (?), Vironus i Viroti (gen.), cap d'ells present en terres valencianes (Abascal 1994: 546-547). En el cas més probable que es tracte del nomen, coneixem diversos casos entre l'antroponímia hispànica que comencen per VIP-/ VIR-: Vipsania, Vipstanus, Virbia, Vireia, Virgilius, Virguleius, Viria/-us, Viriacius, Virillius, Virinius, Vironius i Virria (Abascal 1994: 248-249). De tots, l'únic present en terres valencianes és Viria/-us, que apareix en dos casos a Valentia: C. Virius C.f. Gal. Nepos i la rica lliberta Viria Acte, ben relacionada amb l'aristocràcia valentina, de qui es conserven cinc inscripcions (IRPV V, $9,35,36,37,38,39)$. Considerem més probable, doncs, que es tracte de Virius, un gentilici poc freqüent a Hispània (Pena 2002: 273), on s'ha documentat només en altres set ocasions, i també en el conjunt de l'Imperi (Solin i Salomies 1994: 210). De procedència itàlica, sembla tractar-se de la llatinització d'un nom osc (Barreda 1998: 289-291). Per la datació que donem al monument, aquest personatge possiblement anomenat Virius i present a la vil·la de l'horta Vella seria el més antic dels tres que coneixem fins ara a Valentia i el seu territori, ja que les inscripcions de Viria Acte es daten entre el final del s. I i principis del II i la de C. Virius C.f. Gal. Nepos és del s. II.

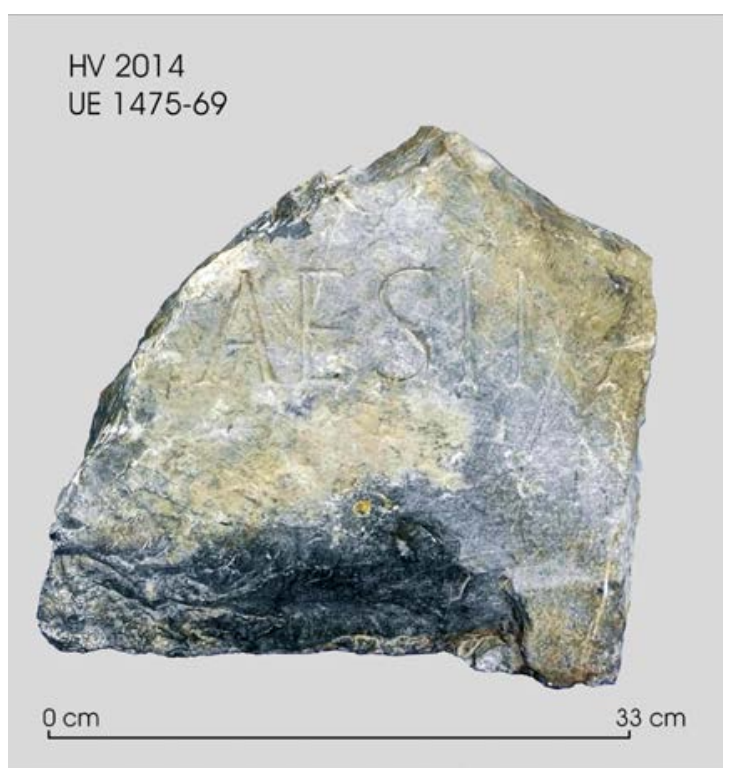

Fig. 3: Fragment núm. 1-b.

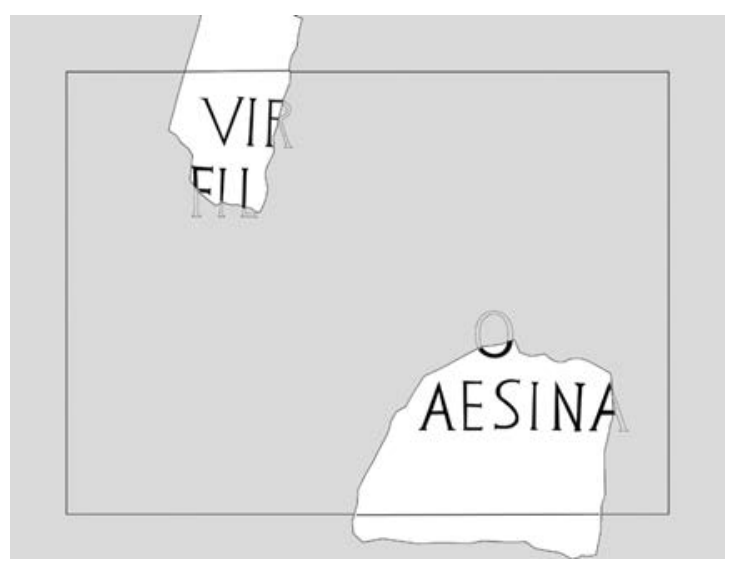

Fig. 4: Restitució hipotètica del monument núm. 1 amb la posició aproximada dels fragments recuperats.

Pel que fa al cognom que apareix en el segon fragment, del qual es pot llegir el final -]aesina, sobre dades de l'EDCS (27/05/2017), aquesta terminació figura en un total de vuit cognoms: Balaesina, Blaesina, Caesina, Halaesina, Laesina (masc.), Paesina, Spaesina $i$ Vaesina. D'aquests, es troben a la península Ibèrica: [B]laesina (Cadis) (AE 1995, 792) i P[a]esina (Navarra), tot i que cap d'ells figura en el recull d'Abascal (1994). Quant a la part que falta, considerem que només amb el reforç no és possible determinar la lletra precedent, de manera que la restitució del cognom queda oberta. 
A pesar de l'estat fragmentari del monument, pensem que probablement es tracta d'un epígraf funerari en què es conserva part del nom del difunt i del cognom de la dedicant. La coincidència entre el probable radical Vir- que figura en la primera línia i el gentilici Viria/-us, documentat a Valentia, ens porta a considerar més probable aquesta restitució, el que permet plantejar la possible vinculació entre aquesta important família valentina i el fundus de l'horta Vella. Per la mateixa raó, són escassos els criteris que poden aplicar-se per a la datació, però la probable absència de la dedicatòria als déus Mans i la bona factura de la lletra ens porten a proposar una datació en la primera meitat o mitjans del s. I dE.

2) Petit fragment d'una llosa de calcària de color gris fosc amb vetes blanques. Les seues dimensions són 17,7 x 8,5 x 7,8 cm (fig. 5).

L'altura de les lletres és de 7,3 cm i la interlineació d'1,7 cm. El camp epigràfic està allisat i conserva traces fines de poliment. La lletra és elegant, de solc un poc irregular, i compta amb reforços. Conserva un

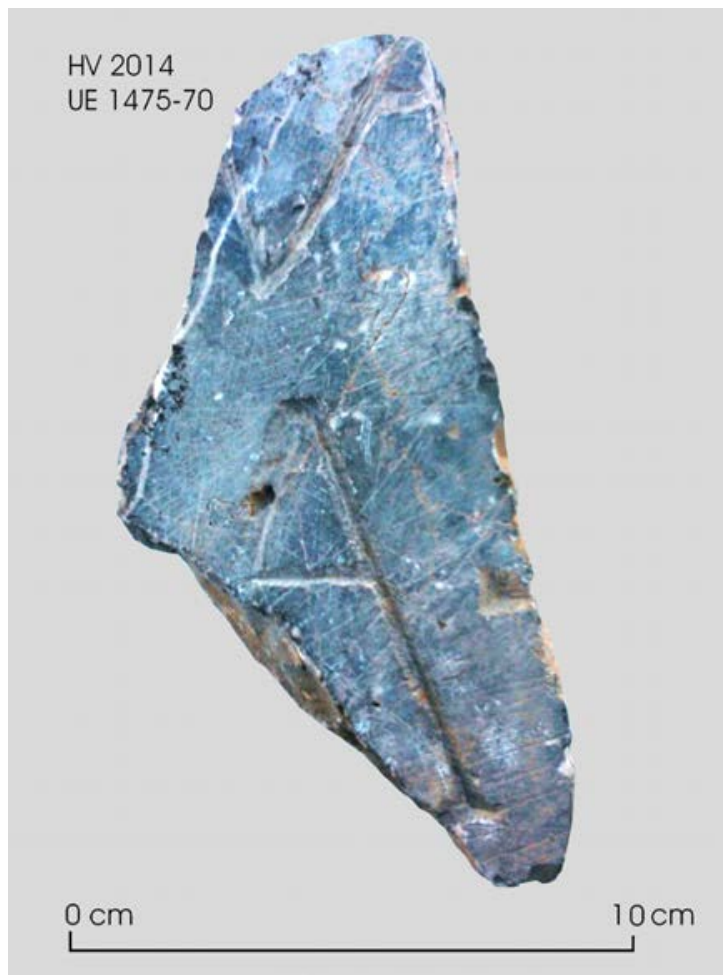

Fig. 5: Fragment núm. 2. punt triangular amb un vèrtex cap amunt. Només hi ha dues lletres incompletes: en la primera línia s'hi veu el que sembla una $\mathrm{M}$ incompleta $\mathrm{i}$ en la segona una $\mathrm{A}$ també incompleta però de lectura segura, seguida d'un punt triangular. Òbviament, a causa de l'estat fragmentari de l'epígraf no se'n pot fer cap deducció, més enllà d'una datació entre els ss. I-II.

$$
\begin{aligned}
& -----? \\
& {[---] M[---]} \\
& {[---] A \cdot[---]} \\
& -----?
\end{aligned}
$$

Tot i que es tracta de fragments molt reduïts, són les primeres troballes epigràfiques d'aquesta vil·la situada el territori de Valentia, el que els dóna un important valor que s'acreix amb la possible identificació del gentilici del propietari, que podria ser Virius i estar relacionat amb aquesta família documentada a la colònia.

\section{NOTA}

1. Volem agrair als professors J. M. Abascal (Universitat d'Alacant) i P. P. Ripollès (Universitat de València) la lectura prèvia del manuscrit i les seues indicacions.

\section{BIBLIOGRAFIA}

ABASCAL, J. M. (1994): Los nombres personales en las inscripciones latinas de Hispania, Murcia.

BARREDA, A. (1998): Gentes itálicas en Hispania Citerior (218 a.C.-14 d.C.) Los casos de Tarraco, Carthago Nova y Valentia, Tesi Doctoral, Universitat Autònoma de Barcelona.

EDCS = Epigraphik-Datenbank Clauss/Slaby: http://www.manfredclauss.de/

IRPV V = CORELL I VICENT, J. (2009): Inscripcions romanes del País Valencià. V. Valentia i el seu territori, València.

JIMÉNEZ, J. L.; ARANEGUI, C.; BURRIEL, J. M. (2013): La definición territorial del triángulo Saguntum-ValentiaEdeta: estado de la cuestión, Paisajes rurales y territorios en la ciudades del Occidente Romano. Gallia e Hispania, Actes du colloque International AGER IX (J.-L. Fiches, R. Plana-Mallart, V. Revilla, eds.), Montpellier, 109-119.

JIMÉNEZ, J. L.; BURRIEL, J. M.; LORENA, A. (2011): IX campaña de excavaciones en el yacimiento romano de L'Horta Vella (Bétera, Valencia), Saguntum-PLAV 43: 219-222. 
JIMÉNEZ, J. L.; BURRIEL, J. M.; ORTEGA, M. J.; ROSSELLÓ, M.; RUIZ, L. (2012): L’Horta Vella (Bétera, València), Actes del Simposi Les vil.les romanes a la Tarraconense. Implantació, evolució i transformació. Estat actual de la investigació del món rural en època romana, Barcelona, 175-182.

JIMÉNEZ, J. L.; BURRIEL, J. M.; ROSSELLÓ, M.; SERRANO, M.; SALAVERT, J. V. (2008): La fase tardorromana de l'Horta
Vella (Bétera, Valencia), Las villae tardorromanas en el Occidente del Imperio. Arquitectura y función (C. Fernández Ochoa, V. García Entero, F. Gil Sendin, eds.), Gijón, 629-638.

PENA, M. J. (2002): Problemas históricos en torno a la fundación de Valentia, Valencia y las primeras ciudades romanas de Hispania (J. L. Jiménez, A Ribera, eds.), Valencia, 267-278.

SOLIN, H.; SALOMIES, O. (1994): Repertorium nominum gentilium et cognominum latinorum, Olms-Weidmann.. 